\title{
Xeroderma Pigmentosum-A Rare Genodermatosis: Overview of Literature
}

\author{
Shamimul Hasan ${ }^{1 *}$ and Shazina Saeed ${ }^{2}$ \\ ${ }^{1}$ Department of Oral Medicine and Radiology, Faculty of dentistry, Jamia Millia Islamia, New Delhi, India \\ ${ }^{2}$ Amity Institute of Public Health, Amity University, Noida, UP, India
}

\begin{abstract}
Xeroderma pigmentosum is a rare genodermatosis, autosomal recessive in nature in which excessive ultraviolet radiation causes skin, ocular, neurological, and oral lesions along with development of cutaneous and internal malignancies at an early age. There is no definitive cure for the disease. Avoidance of ultraviolet radiation, use of protective clothing, sunscreens, oral retinoids, 5-fluorouracil and regular consultations with dermatologists, ophthalmologists, neurologists and dentists forms an important part of the treatment protocol. This paper aims to throw light on the etiopathogenesis, clinical features and treatment modalities of this life threatening disease. There is also a special mention on the oral manifestations and dental health considerations of the rare disorder.
\end{abstract}

Keywords: Xeroderma pigmentosum; Ultraviolet radiation; Cutaneous lesions; Dental health considerations

\section{Introduction}

Xeroderma pigmentosum (XP) is a rare genetic autosomal recessive disease marked by extreme photosensitivity, hyperpigmentation and premature ageing of the skin, along with the development of cutaneous and internal malignancies at an early age. There is a defect in the nucleotide excision repair (NER) mechanism which results in a defective repair of DNA damaged by ultraviolet (UV) radiation [1]. XP is widespread in all continents and all racial groups are affected. As the disorder has an autosomal recessive inheritance, both males and females are affected. The reported incidence rate (estimates made in the 1970's) was 1: 250,000 [2] and 1: 20,000 in the USA and Japan respectively, with a rare occurrence in India [3]. Recent survey analysis in Western Europe suggested an incidence of approximately 2.3 per million live births [4]. As consanguinity is highly prevalent in North Africa and the Middle East, the incidence rate of XP in these areas is substantially higher. The disease is categorized into eight forms based on the clinical aspects and the patterns of the molecular defect [5]. The diagnosis of $\mathrm{XP}$ can be established by studies performed in specialized laboratories. These studies include cellular hypersensitivity to UV radiation and chromosomal breakage studies, complementation studies, and gene sequencing to identify the specific gene complementation group [6]. Early and rigorous photoprotection with sun avoidance, sunscreens and appropriate clothing forms a part of treatment plan. DNA repair enzymes and oral retinoids are currently under clinical trials and show a hope for the future $[7,8]$.

\section{Discussion}

Xeroderma pigmentosum (XP) is a rare autosomal recessive, progressive, degenerative disease which is related to photosensitivity, cutaneous pigmentation, abnormal DNA repair, various neoplasms and occasionally, neurologic degeneration [9].

Xeroderma pigmentosa (XP) was described by Dr. Moriz Kaposi in 1870, a dermatologist in Vienna [10]. The term "xeroderma or parchment skin" was initially described and in 1882, the term "pigmentosum" was added to emphasize the striking pigmentary abnormality [11].

\section{Etiopathogenesis}

\section{Exposure to UV radiation}

Ultraviolet (UV) irradiation is composed of UV A spectrum and UV B spectrum, where UVB plays an important role in the etiology of
XP. UV irradiation causes photoproducts in DNA, chiefly cyclobutane pyrimidine dimers (CPDs) and 6-pyrimidine-4-pyrimidone, which further brings about cell death, mutagenesis, carcinogenesis and cellular ageing [12]. XP is an autosomal recessive disorder which results from mutations in any of the eight genes. These genes restore the DNA damage induced by UV radiation by a process known as nucleotide excision repair (NER) [13]. XP patients have mutations in one or more NER genes, and cause molecular defects in cellular DNA repair mechanisms and hypersensitivity to UV radiation. As a result, the accumulation of unrepaired UV induced DNA damage occurs which either facilitate cell death, contributing to accelerated skin ageing, or cellular transformation resulting in the development of malignancies [14-16].

Many XP patients with tumors show mutations in the p53 gene, indicating that p53 mutations are characteristic of UV exposure [17].

\section{Consanguinity}

Consanguinity has been implicated as an etiological factor. This has been reported to varying degrees of up to $92.8 \%$ in XP patients in Libya [18]. Other studies reported from Egypt, Pakistan, and Nigeria etc. have a high incidence of XP [19]. However, a case report by Stephanic Christen et al. showed a family where the uncle and nephew were affected by XP [20].

\section{Drugs and Chemicals}

A number of DNA-damaging agents apart from UV radiation have been implicated to cause a hypersensitive response to XP cell [21] (Table 1).

\section{Clinical Features}

Most clinical features are subject to amount of exposure to sunlight, the complementation group, the mutation, and some unknown factors.

*Corresponding author: Shamimul Hasan, Department of Oral Medicine and Radiology, Faculty of Dentistry, Jamia Millia Islamia, New Delhi, India, Tel: 09953290676; E-mail: shamim0571@gmail.com

Received November 10, 2015; Accepted December 07, 2015; Published December 12, 2015

Citation: Hasan S, Saeed S (2015) Xeroderma Pigmentosum-A Rare Genodermatosis: Overview of Literature. Pigmentary Disorders 2: 230. doi:10.4172/2376-0427.1000230

Copyright: @ 2015 Hasan S, et al. This is an open-access article distributed under the terms of the Creative Commons Attribution License, which permits unrestricted use, distribution, and reproduction in any medium, provided the original author and source are credited. 


\begin{tabular}{|l|l|}
\hline Drugs & Carcinogens \\
\hline $\begin{array}{l}\text { 1. Psoralens plus long wavelength UV } \\
\text { radiation (PUVA) }\end{array}$ & 1. Plant toxin-Aflatoxin \\
\hline 2. Chlorpromazine & 2. Alkylating agents-benzo (a) pyrene \\
\hline 3. Nitrofurantoin & 3. Nitroquinilone oxide derivatives \\
\hline 4. Mitomycin C & 4. Acetaminofluorene derivatives \\
\hline 5. Anthramycin & 5. Phenanthrene derivatives \\
\hline 6. Cisplastin and carmustine & \\
\hline
\end{tabular}

Table 1: Drugs and chemicals.

Hence XP patients present with varied clinical manifestations. Factors aggravating the skin lesions include- Sunny weather, outdoor living, fair skin, smoking, poor accessibility of diagnostic amenities, resulting in delayed diagnosis, and improper shield from sunlight. These factors ultimately cause cutaneous pigmentary changes, cutaneous cancers, and early death [22].

\section{Cutaneous lesions}

Extreme photosensitivity is usually the first sign in about $60 \%$ of cases [23]. Lentigines (freckle-like pigmentation) in sun-exposed areas are seen in remaining $40 \% \mathrm{XP}$ patients as early as two years of age. These pigmented areas are seen on the nose, zygoma, and forehead and followed by the sides of the neck, sparing the area under the chin [22] (Figure 1). Photophobia is often present [24].

Lack of sunlight avoidance causes skin ageing, making it dry, rough, and atrophic. With subsequent sun exposure, lentigines increase in number and darken. They then become difficult to distinguish clinically from flat, pigmented seborrhoeic warts, which also proliferate and become warty with time. Small, hypo-pigmented macules are commonly seen amongst the lentigines and give rise to the characteristic mottled hyper-pigmented and hypo-pigmented appearance known as salt and pepper pattern of skin [21,25] (Figure 2). Atrophic, hypo-pigmented patch is often seen on the skin of the nose in these patients. Telangiectasia can be a late manifestation.

In the general population, Dark-skinned individuals usually have a lower incidence of skin cancer compared to light skinned people. This most probably occurs due to the photo protective properties of melanin. However, in XP, skin cancers occur with an equal frequency in both dark-skinned and light-skinned people, thus highlighting the important role of DNA repair mechanisms even in the presence of photo protective properties of melanin [26].

Excessive sun exposure usually results in areas of hyper- and hypopigmentation, followed by skin ageing, warty growth, melanocyte and keratinocyte malignancy, and ultimately multiple basal cell carcinomas and invasive squamous cell carcinomas and melanomas $[22,23]$. The risk of cutaneous basal cell or squamous cell carcinoma or melanoma is increased to a 1000-fold in XP patients under 20 years of age $[21,27]$. In XP, the median age of onset of non-melanoma skin cancer was 8 years, in contrast to 60 years in the general population [28]. Usually, patients with the most severe repair defects would show the most extreme sunburn reactions and the highest incidence of skin cancer. Paradoxically, patients with acute sunburn reactions develop fewer skin cancers than those who do not. An early diagnosis of the former group and a disinclination of this group to go out in sunlight without protection is likely to play an important role.

\section{Ocular lesions}

Approximately $40 \%$ of XP patients present with ocular lesions like photophobia and blepharospasm, which are the most common. Erythema, pigmentation, atrophy, malignant change, telangectasias, loss of lashes, and chronic blepharitis are less common ocular lesions [29]. Ectropion of the lower eyelid and symblepharon are some symptoms that may occur due to atrophic scarred skin [30]. Corneal opacification, neovascularization, pterygia, and band keratopathy are common, and bandshaped nodular dystrophy and squamous cell carcinomas have also been reported. Keratitis, edema, corneal ulceration and perforation may occur due to lower lid loss [31]. Conjunctival involvement may result in conjunctivitis, pinguecula, symblepharon, melanosis, and tumors developing from the interpalpebral zone of the limbus [29]. Squamous cell carcinomas, malignant melanomas and limbal stem cell deficiency have been often reported. Cases of iritis, stromal atrophy, pigment abnormalities, and, occassionally melanoma have been reported [32]. Fundus abnormalities are less frequently seen because the posterior segment is protected from UV damage by the cornea and lens [33].

\section{Neurological lesions}

Neurological problems are often seen in approximately $20-30 \%$ of the patients. The onset of neurological symptoms usually begins at the
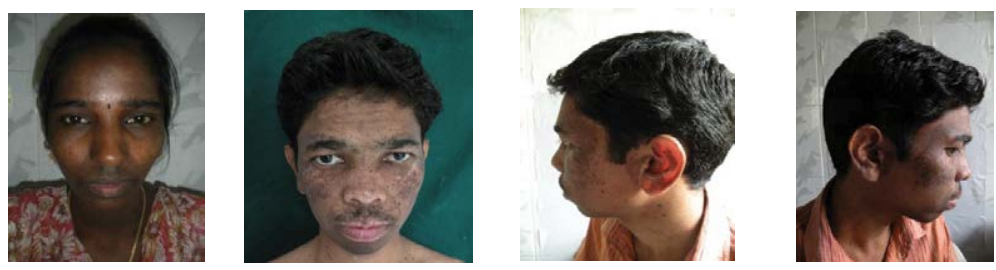

Figure 1: Hyper pigmented macules interspersed with patchy hypopigmentation over face, ear, eyes \& forehead.
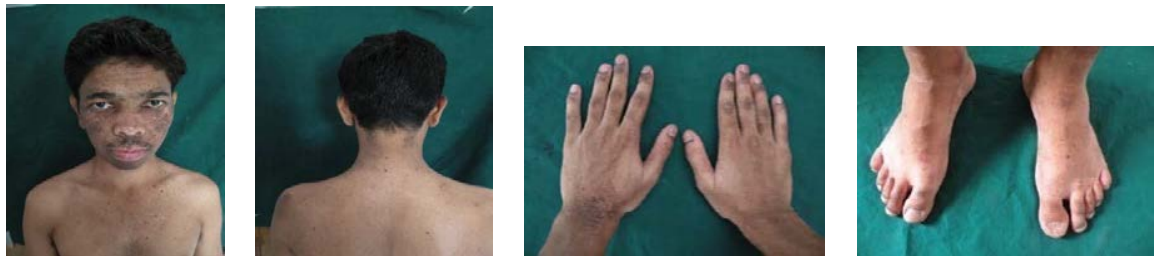

Figure 2: Rough, dry, scaly skin with hyperpigmented macules over the truncal area, back, hands and feet. 
age of two and may occur up to middle age $[23,26]$. The neurological abnormalities include isolated hypo-reflexia, mental retardation, sensorineural deafness, spasticity, or seizures [34].

Loss of high-frequency hearing, is the most common neurological abnormality while the most severe neurological deficits are seen in DeSanctis-Cacchione syndrome [21,35]. The incidence of central nervous system tumors (CNS) is also ten times higher than in the normal population. Some common CNS tumors include, astrocytomas, medulloblastomas, glioblastomas, and malignant schwannoma [31].

\section{Oral lesions}

Oral manifestations are rarely seen and only about $4 \%$ patients exhibit these symptoms [27]. Some common oral manifestations associated with XP are leukoplakia, erythroplakia, Actinic cheilitis and SCC of the tip of the tongue and lips [25]. The precancerous and cancerous lesions of the tip of the tongue are sites that are seldom affected in the normal population and are likely to be induced by UV radiation $[24,26,36]$. SCC of the tip of the tongue in XP patients usually occurs in individuals younger than 20 years of age and progresses slowly [26]. Actinic cheilitis is a potentially malignant lesion that affects the lower lip of white patients who are frequently exposed to the sun. Multiple labial plasty result in areas of fibrosis. Stretching of these fibrosed areas causes pain when the patients opens the mouth for eating, speaking, breathing, and oral hygiene procedures. These patients usually have poor oral hygiene habits and a high rate of dental plaque, caries, and periodontal disease [37]. Cases of chronic desquamative gingivitis, fissured tongue, geographic tongue and keratoacanthoma have also been reported [21,38] (Figures 3-5).

\section{Treatment}

Excessive sun exposure results in irreversible skin damage in XP patients. Treatment protocol aims at minimizing the sun exposure and may include avoidance of being outdoors and use of sunscreen and dark ointments. Avoiding sun exposure for long duration may alter the calcium ion concentration and affect bone growth and development in infants and young children. Dietary supplementation with vitamin D, vitamin $A$ and nicotinamide or zinc sulfate may minimize these side effects [39]. Prophylactic treatment with anticancer drugs, including isotretinoin or fluorouracil can reduce the incidence of skin cancer in XP [40]. Enzymatic treatment and gene therapy have shown good results, but these agents are still in clinical trials [41,42]. Surgical resection is effective in patients who have developed tumors.

\section{Dental considerations}

Important dental health considerations in XP patients include-

1. Use of a UV light meter. The patient may be exposed to a variety

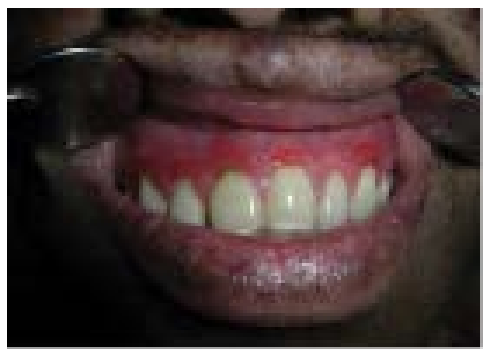

Figure 3: Area of desquamation involving marginal \& attached gingiva in relation to $13-23$.

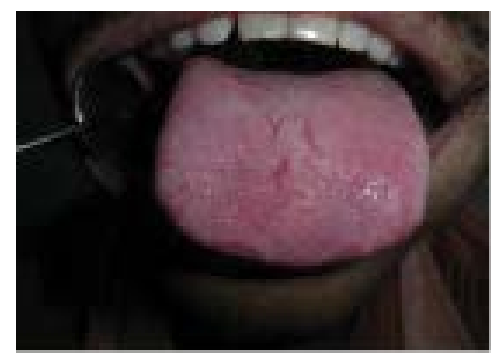

Figure 4: Fissuring over the dorsum of tongue.

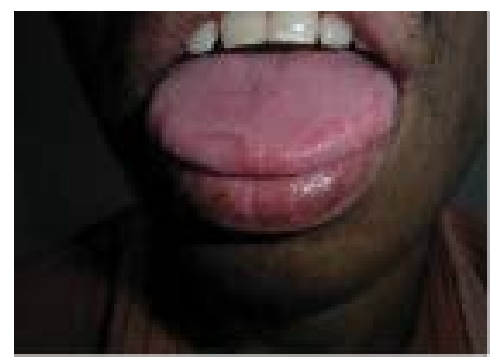

Figure 5: Depapillated areas with whitish circinate borders, suggestive of geographic tongue.

of light sources in the dental office, including overhead lights, view boxes, dental lamps, fiber optic lights, computer screens and dental curing units. If the UV light meter shows a reading above $0 \mathrm{~nm} / \mathrm{cm}^{2}$ for UV light, the use of that unit should be contraindicated.

Although light-emitting diode curing lights emit a wavelength of only $450 \mathrm{~nm}$, [43] the degree of biological damage resulting from such exposure is not sufficiently understood. Restorative materials such as glass ionomers offer a good substitute to resin sealants and composite restorations for treating XP patients [43]. Curing light filters may become ineffective or worn out over time, and allow transmittance of wavelengths in the UVB range (290-320 nm), which are known to have substantial carcinogenic effects on normal epithelium [44,45].

A regular clinical examination is usually a must for timely detection of premalignant or malignant lesions. Furthermore, establishment of protocols for prophylaxis and topical fluoride application, as well as the use of chlorhexidine digluconate $0.12 \%$, aims at the homeostasis of the oral environment. Mouthwashes with high alcohol concentration are usually avoided as it is associated with an increased risk of oral cancer development in these patients [46]. Regular dental procedures, such as dental extraction, restoration and rehabilitation pose a challenge to the dentist due to difficulty in accessing the oral cavity.

Periodic oral examinations are important and usually include complete inspection and palpation of soft tissues (lips, tongue and oral mucosa). Radiation therapy is used to treat the head and neck tumors and are known to cause radiation induced caries and permanent damage to salivary glands. Meticulous oral hygiene procedures such as proper brushing, flossing and fluoride rinses are usually advised for XP patients, as these patients do not maintain routine dental appointments $[43,47]$.

\section{Conclusion}

Xeroderma pigmentosum is a autosomal recessive disorder characterized by UV induced damage to the skin, eyes and nervous 
tissue. Oral lesions are rarely associated with the disorder and include leukoplakia, erythroplakia and carcinomas. There is no cure for the disease, however, clinical trials are in progress to understand the etiopathogenesis and the development of an effective treatment protocol.

\section{References}

1. Cleaver JE (1968) Defective repair replication of DNA in xeroderma pigmentosum. Nature 218: 652-656.

2. Robbins JH, Kraemer KH, Lutzner MA, Festoff BW, Coon HG (1974) Xeroderma pigmentosum: an inherited disease with sun-sensitivity, multiple cutaneous neoplasms, and abnormal DNA repair. Annals Internal Med 80: 221-248.

3. Hirai Y, Kodama Y, Moriwaki S, Noda A, Cullings HM, et al. (2006) Heterozygous individuals bearing a founder mutation in the XPA DNA repair gene comprise nearly $1 \%$ of the Japanese population. Mutat Res 601 : 171-178.

4. Kleijer WJ, Laugel V, Berneburg M, Nardo T, Fawcett H, et al. (2008) Incidence of DNA repair deficiency disorders in western Europe: Xeroderma pigmentosum, Cockayne syndrome and trichothiodystrophy. DNA repair 7: 744-750.

5. Inui H, Oh KS, Nadem C, Ueda T, Khan SG, et al. (2008) Xeroderma pigmentosum-variant patients from America, Europe, and Asia. J Invest Dermatol 128: 2055-2068.

6. Horenstein MG, Diwan AH (2005) "Xeroderma Pigmentosum".

7. Kraemer KH, DiGiovanna JJ, Moshell AN, Tarone RE, Peck GL (1988) Prevention of skin cancer in xeroderma pigmentosum with the use of oral isotretinoin. N Engl J Med 318: 1633-1637.

8. Yarosh D, Klein J, O'Connor A, Hawk J, Rafal E, Wolf P (2001) Effects of topically applied T4 endonuclease $\mathrm{V}$ in liposomes on skin cancer in xeroderma pigmentosum: a randomised study. Xeroderma pigmentosum study group. Lancet 357: 926-929.

9. Kraemer KH, Slor H (1985) Xeroderma pigmentosum. Clin Dermatol 3: 33-69.

10. Hebra F, Kaposi M (1874) On disease of the skin including exanthemata. New Sydenham Soc 61: 252-258.

11. Kaposi M (1883) Xeroderma pigmentosa. Ann Dermatol Venereol 4: 29-38

12. Moriwaki S, Kraemer KH (2001) Xeroderma pigmentosum--bridging a gap between clinic and laboratory. Photodermatol Photoimmunol Photomed 17: 47-54.

13. Stefanini M, Kraemer KH (2008) Xeroderma pigmentosum in Neurocutaneous Diseases.

14. Andressoo JO, Weeda G, De Wit J (2009) An Xpb mouse model for combined xeroderma pigmentosum and cockaynesyndrome reveals progeroid features upon further attenuation of DNA repair. Molecular and Cellular Biology 29 1276-1290.

15. Bunick CG, Miller MR, Fuller BE, Fanning E, Chazin, et al. (2006) Biochemica and structural domain analysis of xeroderma pigmentosum complementation group C protein. Biochemistry 45: 14965-14979.

16. Stoyanova T, Yoon T, Kopanja D, Mokyr MB, Raychaudhuri, et al. (2008) “The xeroderma pigmentosum group $\mathrm{E}$ gene productDDB2 activates nucleotide excision repair by regulating the level of p21Waf1/Cip1". Molecular and Cellular Biology 28: 177-187.

17. Grosjean D, Sarasin S (2005) "The role of UV induced lesions in skin carcinogenesis: an overview of oncogene and tumor suppressor gene modifications in xeroderma pigmentosum skin tumors". Mutation Research 571: 43-56.

18. Khatri ML, Bemghazil M, Shafi M, Machina A (1999) Xeroderma pigmentosum in Libya. Int J Dermatol 38: 520-524.

19. Ahmed H, Hassan RY, Pindiga UH (2001) "Xeroderma pigmentosumin three consecutive siblings of a nigerian family: observations on oculocutaneous manifestations in black African children". British Journal of Ophthalmology 85 $110-111$.

20. Christen-Zaech S, Imoto K, Khan SG, Oh KS, Tamura D, et al. (2009) Unexpected occurrence of xeroderma pigmentosum in an uncle and nephew. Arch Dermatol 145: 1285-1291.

21. Hasan S, Khan MA(2011)Xeroderma pigmentosum with desquamativegingivitis:
A rare case report and detailed review of literature. Journal of cosmetics Dermatological Sciences and Applications 1: 164-170.

22. Lehmann AR, McGibbon D, Stefanini M (2011) Xeroderma pigmentosum. Orphanet J Rare Dis 6: 70.

23. Bradford PT, Goldstein AM, Tamura D, Khan SG, Ueda T, et al. (2011) Cancer and neurologic degeneration in xeroderma pigmentosum: long term follow-up characterises the role of DNA repair. J Med Genet 48: 168-176.

24. Rünger TM, DiGiovanna JJ (2008) "Hereditary disorders of genome instability and DNA repair". Fitzpatrick's Dermatology in General Medicine, McGraw-Hill, New York, USA.

25. Feller L, Wood NH, Motswaledi MH, Khammissa RA, Meyer M, et al. (2010) Xeroderma pigmentosum: a case report and review of the literature. J Prev Med Hyg 51: 87-91.

26. Mahindra P, DiGiovanna JJ, Tamura D, Brahim JS, Hornyak TJ, et al. (2008) Skin cancers, blindness, and anterior tongue mass in African brothers. J Am Acad Dermatol 59: 881-886.

27. Kraemer KH, Lee MM, Scotto J (1987) Xeroderma pigmentosum. Cutaneous, ocular, and neurologic abnormalities in 830 published cases. Arch Dermato 123: $241-250$.

28. Kraemer KH, Lee MM, Andrews AD, Lambert WC (1994) "The role of sunlight and DNA repair in melanoma and nonmelanoma skin cancer: The xeroderma pigmentosum paradigm". Archives of Dermatology 130: 1018-1021.

29. el Hefnawi H, Rasheed A (1966) Xeroderma pigmentosum. A report of furthe six cases. J Egypt Med Assoc 49: 419-434.

30. Reese AB, Wilber IE (1943) The eye manifestations of xeroderma pigmentosum American Journal of Ophthalmology 26: 901-911.

31. Blanksma LJ, Donders PC, van Voorst Vader PC (1986) Xeroderma pigmentosum and keratoconus. Doc Ophthalmol 64: 97-103.

32. Johnson MW, Skuta GL, Kincaid MC, Nelson CC, Wolter JR (1989) Malignant melanoma of the iris in xeroderma pigmentosum. Arch Ophthalmol 107: 402 407.

33. Kitagawa KOT, Inoue M (1981) Choroidal malignant melanoma occurring in a patient with xeroderma pigmentosum. Folia OphthalmolJpn 37: 657-663.

34. Kraemer KH (2003) Heritable diseases with increased sensitivity to cellular injury. Fitzpatrick's Dermatology in General Medicine. McGraw-Hill, New York USA.

35. Robbins JH, Brumback RA, Moshell AN (1993) Clinically asymptomatic xerodermapigmentosum neurological disease in an adult: evidence for a neurodegeneration in later life caused by defective DNA repair. European Neurology 33: 188-190.

36. Neville BW, Damm DD, Allen CM (2009) Dermatologic diseases. Oral and Maxillofacial Pathology. (3rd edn), Saunders Elsevier, USA.

37. Lopes-Cardoso C, Paes da Silva Ramos Fernandes LM, Ferreira-Rocha J, Teixeira-Soares C, Antônio-Barreto J, et al. (2012) Xeroderma Pigmentosum A case report with oral implications. J Clin Exp Dent 4: e248-251.

38. Saawarn N, Shashikanth M, Saawarn S, Jirge V, Chaitanya N, et al. (2011) Lycopene in the management of oral lichen planus: a placebo-controlled study. Indian Journal of Dental Research 22: 639-643.

39. Ali JT, Mukasa Y, Coulson IH (2009) Xeroderma pigmentosum: early diagnostic features and an adverse consequence of photoprotection. Clin Exp Dermato 34: $442-443$

40. Stockfleth E (2009) Topical management of actinic keratosis and field cancerisation. G Ital Dermatol Venereol 144: 459-462.

41. Zahid S, Brownell I (2008) Repairing DNA damage in xeroderma pigmentosum: T4N5 lotion and gene therapy. J Drugs Dermatol 7: 405-408.

42. Menck CF, Armelini MG, Lima-Bessa KM (2007) On the search for skin gene therapy strategies of xeroderma pigmentosum disease. Curr Gene Ther 7: 163

43. Park S, Dock M (2003) Xeroderma pigmentosum: a case report. Pediatr Dent 25: $397-400$

44. Epstein JH (1970) Ultraviolet carcinogenesis. Photophysiology 5: 235-273.

45. Setlow RB (1974) The wavelengths in sunlight effective in producing skin cancer: a theoretical analysis. Proc Natl Acad Sci U S A 71: 3363-3366. 
Citation: Hasan S, Saeed S (2015) Xeroderma Pigmentosum-A Rare Genodermatosis: Overview of Literature. Pigmentary Disorders 2: 230. doi:10.4172/2376-0427.1000230

Page 5 of 5

46. Scully C (1995) Oral precancer: preventive and medical approaches to management. Eur J Cancer B Oral Oncol 31B: 16-26.
47. Patton LL, Valdez IH (1991) Xeroderma pigmentosum: review and report of a case. Oral Surg Oral Med Oral Pathol 71: 297-300. 